\title{
REVITALISASI NILAI DALAM DONGENG SEBAGAI WAHANA PEMBENTUKAN KARAKTER ANAK USIA DINI
}

\author{
Juanda \\ Fakultas Bahasa dan Sastra, Universitas Negeri Makassar, Indonesia \\ Juanda@unm.ac.id.
}

Naskah diterima: 4 Juni ; direvisi: 21Juni; disetujui: 28 Juni

\begin{abstract}
Abstrak
Peranan bacaan anak dalam pembentukan karakter anak usia dini sangat penting. Begitu pula peranan pendidikan karakter sangat diperlukan oleh pemerintah sebagai dasar pendidikan di Indonesia. Oleh karena itu, penelitian ini bertujuan menggali nilainilai pendidikan karakter dalam dongeng serta peranannya dalam pembentukan pribadi anak usia dini. Pendekatan yang digunakan adalah konsep sastra anak dan pendidikan karakter. Metode yang dipakai yaitu penelitian deskriptif kualitatif dengan teknik analisis isi. Sumber data berasal dari media kompas yakni dongeng bertemakan pendidikan karakter yang dianalisis. Nilai pendidikan karakter yang ditemukan dalam dongeng "Suri Ikun dan Dua Ekor Burung" yakni, nilai kreatif dan kerja keras, penolong, menghargai prestasi, sikap positif dan nilai kejujuran.
\end{abstract}

Kata Kunci: Sastra Anak, Dongeng, dan Karakter

\begin{abstract}
The role of child reading in the formation of early childhood character is very important. So also the role of character education is needed by the government as the basis of education in Indonesia. Therefore, this study aims to explore the values of character education in the folktale and is role in the formation of personal early childhood. The approach used is the consept of childrens's literature and character education. The method used is descriptive qualitative research with content analysis techniques. The source of data derived from the media compass that is a strory-theme tales character of the analyzed. The value of character education found in the folktales of "Suri Ikun and Two Bird's" that is creative value, hardwork, helpers, appreciate achievement, positive attitude, and honesty value.
\end{abstract}

\section{Keywords: Literature of children, folktale, and Character}

\section{Pendahuluan}

Apabila kita sering melihat berita di media, tentu kita banyak melihat persoalan akhlak menyimpang yang dilakukan oleh anak remaja hingga dewasa. Contoh sederhana adalah berita tentang penghinaan yang dilakukan oleh seorang remaja SMA kepada bapak presiden yang terjadi disekolah sebagai bahan taruhan. Media beranggapan bahwa kejadian tersebut sebagai bentuk eksistensi anak milenial yang ingin menunjukkan pengakuan jati diri mereka. Hal ini menunjukkan bahwa impian menjadi insan berkarakter dan berakhlak mulia masih jauh dari harapan kita semua. Padahal jati diri yang ideal sebenarnya adalah membentuk insan yang beriman, cerdas, kreatif, inovatif dan tentunya mampu menghasilkan karya yang bermanfaat.

Pengaruh budaya global yang begitu deras mengakibatkan bergesernya nilai-nilai kearifan lokal kita sendiri, seperti nilai-nilai sipakatau, sipakalebbi, dan sipakainga. Nilai tersebut hanya seperti sebuah simbol atau mainan yang tidak diresapi oleh setiap insan, baik anak remaja hingga dewasa. Dalam bentuk lain, pada jaman sekarang dan cerita-cerita budaya yang berasal dari luar dibentuk dengan memakai alat modern seperti permainan berbentuk gadget dan handphone lewat internet merupakan hal 'kekinian'. selanjutnya tanpa disadari budaya ini dapat membuat karakter 
negative kepada anak, misalnya horor, kekerasan, pornografi, dan sebagainya (Adhi, 2014).

Membentuk pribadi berkarakter adalah angan-angan luhur bangsa yang pada masa sekarang masih banyak rintangan (Nurgyantoro, 2010). Pengaruh budaya global sebagai salah satu hal penyebab degradasi moral anak generasi penerus bangsa kita. Menurut Suryaman (2010) (Herfanda, 2008, hlm. 131) sastra memiliki peluang utama dalam pembentukan dan perubahan karakter. Melalui karya sastra kita akan mempelajari berbagai nilai-nilai yang bersifat kemanusiaan mengenai hubungan antara manusia secara horizontal dan spiritual sebagai manusia yang beriman kepada Allah SWT, serta menghargai segala yang ada dalam kehidupan sekitar kita.

Wellek dan Warren (1993); (Yasid, 2012) sastrasebagai sebuah karya estetika yang dihasilkan lewat proses kreatif. Selain itu, karya sastra sebagai hasil imajinatif yang memiliki pengertian lebih luas daripada karya nonfiksi. Karya sastra sebagai cerminan segala permasalahan dunia dengan segala kerumitannya dengan berbagai persoalan yang ada di dalamnya.

Menurut Suparno (2002); (Untari, dkk., 2012) bahwa melalui pendidikan bahasa dan sastra Indonesia berpeluang utama untuk memberikan pemahaman karakter bagi anak usia dini lewat cerita anak. Sebab seyogyanya karakter anak harus dibentuk sejak usia dini. Namun, cerita anak yang disajikan harus sesuai dengan pertumbuhan dan perkembangan anak, serta sastra anak tersebut wajib mengandung nilai budi pekerti.

Penelitian mengenai kajian nilai pendidikan karakter telah banyak dilakukan oleh para ahli diantaranya, (Nurgiyantoro, 2010); (Yasid, 2012); (Untari, dkk., 2012); (Adhi, M.K., 2014); (Oktavianus, Ike Revita, dan Dian Astri, 2014). Namun, penelitian tersebut belum memfokuskan kajiannya pada dongeng yang berasal dari NTT khususnya Suri Ikun dan Dua Ekor Burung.

Berbagai upaya telah ditempuh untuk memperbaiki karakter anak bangsa kita diantaranya melalui pengkajian nilai karakter menggunakan berbagai pendekatan disiplin ilmu. Namun, pada kenyataannya kemerosotan akhlak terus terjadi bahkan hingga ke titik yang paling kritis disebut yakni, degradasi moral. Sementara itu (Afandi, 2011) mengemukakan bahwa beberapa negara lain telah menerapkan pendidikan karakter sejak usia dini. Negara tersebut antara lain, Cina, Amerika, Jepang, dan Korea. Hasil penelitian mereka menunjukkan bahwa penanaman pendidikan karakter yang mereka terapkan mendapat hasil yang positif. Penanaman karakter dilakukan secara sistematis sejak usia dini dan hasilnya berdampak positif termasuk dalam pencapaian akademis. Karya sastra harus diperkenalkan kepada anak mulai usia dini. Hal ini bertujuan supaya kecakapan literasi berkembang supaya kebiasaan berimajinasi dan berkreasi tercipta. Kemampuan tersebut tidak mungkin muncul tanpa usaha sadar dan terstruktur. Usaha yang sadar dan direncanakan secara matang itu dapat dilakukan melalui pendidikan yang lebih menitik beratkan pada potensi alamiah yang ada pada peserta didik khususnya minat dan bakat dalam bidang sastra (Yasid, 2012:47). Berikutnya, Oktavianus, Ike Revita, dan Dian Astri (2014) mengeksplorasi nilai karakter peribahasa Minangkabau, antara lain nilai pendidikan karakter yang berkaitan dengan antikorupsi.

Dari uraian tersebut di atas, pokok permasalahan pada penelitian ini adalah bagaimanakah bentuk atau peranan karya sastra tradisional (dongeng) khususnya dalam membentuk kepribadian anak. Sesuai dengan permasalahan ini penulis menentukan menentukan tujuan penelitian yaitu memaparkan sastra anak, dongeng sebagai karya sastra, dan perananannya dalam pembentukan pribadi yang berkarakter bagi anak. Penelitian ini memiliki urgensi menggali kembali nilai-nilai yang ada dalam sastra daerah, khususnya sastra daerah yang berasal dari Nusa Tenggra Timur. Sastra daerah ini penting diekplorasi nilai-nilai yang ada di dalamnya sehingga dapat dijadikan bahan pengayaan bahan ajar di sekolah.

Karya sastra menawarkan dua permasalahan utama, yakni kepahaman tentang kehidupan dan kesenangan. Sastra memberikan hiburan yang menyenangkan (Nurgiyantoro, 2016). Sastra menyajikan cerita menarik melalui pemakaian bahasa yang tidak lazim. Sastra memberikan imajinasi pembacanya, mengajak pembaca untuk berfantasi, memberikan daya suspense, serta menarik hati pembacanya. Oleh karena itu, sastra dianggap memainkan emosi pembacanya sehingga ikut larut dalam imajinasi pengarangnya.

Sastra anak merupakan karya yang dikhususkan bagi anak. Kandungan isi buku- 
buku sesuai dunia, minat dengan tidak mengesampingkan aspek emosional dan intelektual anak. Anak berbeda orang dewasa pada tingkat pengalaman dan kematangan. Anak juga terbatas dalam hal penggunaan bahasa dan kalimat bersifat kompleks. Oleh karena itu, bahasa yang digunakan bagisastra anak usia dini harus menggunakan kosakata, struktur dan ungkapan sederhana.

Budaya mendongengkan merupakan hal yang baik dan disukai oleh anak usia dini (Adhi, 2014). Sebab, dengan mendongengkan anak kecil, secara tidak langsung kita telah menanamkan nilai-nilai dalam dirinya, baik nilai personal maupun nilai pendidikan pada anak itu. Melalui menceritakan atau mendongengkan kita dapat meningkatkan daya imajinasi, emosional, intelektual, rasa sosial, rasa etis dan religius. Oleh karena itu, orang tua perlu memilihkan jenis dongeng yang benarbenar sesuai dengan perkembangan anak.

Pendidikan karakter sangat diperlukan oleh pemerintah sebagai dasar pendidikan Indonesia (Septiana, 2012). Karakter diartikan sebagai tabiat, yakni perbuatan, watak, perilaku, atau kebiasaan yang selalu dilakukan. Pembelajaran bahasa Indonesia juga dianggap penting untuk memberikan sumbangsi penanam karakter pada anak melalui empat kemahiran berbahasa: menyimak, berbicara, membaca dan menulis (Wulandari, 2015). Pembentukan karakter dapat diaplikasikan dalam perilaku sehari-hari di sekolah seperti merawat serta menjaga lingkungan dengan menanam tanaman, peduli trhadap sesama, dan sikap-sikap mulia lainnya. Karakter baik atau jelek tercipta melalui latihan dan pembiasaan secara rutin (Setiawati, 2015, hlm.72).

Kementerian Pendidikan Nasional menyebutkan nilai karakter. Nilai karakter tersebut berupa: religius; kejujuran; toleransi; kedisiplinan; bekerja keras; kreatif; mandiri; demokratis; muncul rasa ingin mengetahui; jiwa kebangsaan; cinta tanah air; berprestasi; bersahabat, omunikatif; cinta damai; gemar membaca; peduli; peduli lingkungan; dan bertanggung jawab (Suprapto, 2014).

Secara spesifik Ratna dalam (Ikhwan, 2013,hlm. 74) menyebutkan tiga unsur yang harus dilakukan dalam model pendidikan karakter, yaitu: knowing, feeling, dan acting dalam hal kebaikan. Jadi, sejak kecil anak sudah perlu ditanamkan pada diri mereka pengetahuan mengenai kebaikan; melatih anak untuk selalu merasa cinta dalam melakukan kebaikan; anak dilatih berbuat baik agar menjadi kebiasaan yang paten pada dirinya dan kehidupan sehari-hari.

\section{Metode}

Penelitian ini menggunakan peneltian deskriptif kualitatif dengan menganalisis karakter tokoh utama dalam dongeng. Teknik yang digunakan adalah teknik analisis isi dengan menggunakan sumber data dari dongeng. Analisis data dilakukan dengan membaca seluruh isi dongeng lalu menganalisis nilai pendidikan karakter tokoh utamapada teks dongeng. Dongeng sebagai sastra anak yang dianalisis dalam penelitian ini dan berfungsi sumber data yaitu dongeng "Suri Ikun dan Dua Ekor Burung". Data diperoleh melalui sumber media kompas/lakonhidup.com.

\section{Hasil dan Pembahasan}

Dongeng Suri Ikun dan Dua Ekor Burung, selanjutnya disingkat (SIDB) mengisahkan kehidupan keluarga miskin di Nusa Tenggara Timur yang mempunyai 14 orang anak. Tujuh laki-laki dan tujuh perempuan. Anak bungsu laki-laki bernama Suri Ikun yang rajin dan pemberani. Sementara saudara lainnya penakut dan pemalas. Pekerjaan mereka aalah berkebun. Tanaman mereka selalu diganggu oleh babi hutan. Sang ayah menugasi anaknya ronda di kebun menjaga tnamn dari hama babi. Suri ikun membebaskan saudaranya dari pekerjaaan ronda. Dia menjaga kebun sendirian dan berhasil menangkap babi hutan dengan panah.

Pada suatu hari Suri Ikun kehutan mencari kayu bakar bersama saudarasaudaranya. Dia ditinggl sendiri di tengah hutan. Akhirnya ditanggkap oleh raksasa hutan. Di dikurung di dalam gua. Meskipun dikurung dia masih sempat menolong burung kecil yang kelaparan. Makanan yang diberikan kepadanya diberikan kepada burung tersebut. Burung yang selalu diberikan makanan tumbuh menjadi besar dan dapat berbicara seperti manusia. Akhirnya burung tersebut menolong Suri Ikun keluar ari kurungan gua lalu diterbangkan ketempat yang jauh di bukut yang tinggi. Di sana burung tersebut dengan kekuatan gaibnya membangunkan Suri Ikun istana yang lengkap dengan pengawal dan dayang-dayangnya. Akhirnya dia hidup berbahagia. Sementara keluarganya di kampung semakin melarat karena tidak ada lagi Suri Ikun yang rajin bekerja untuk keluarga dan menjaga hama bai di kebun. 
Berdasarkan hasil analisis datadalam teks dongeng "Suri Ikun dan Dua Ekor Burung" (SIDB) ditemukan nilai pendidikan karakter. Nilai-nilai tersebut tercermin dalam perilaku tokoh utama dalam dongeng. Adapun nilai tersebut akan dideskripsikan secara rinci, yaitunilai kreatif dan kerja keras, penolong, menghargai prestasi, sikap positif dan kejujuran. Hasil yang ditemukan sebagai berikut:

\subsection{Kreatif dan Kerja Keras}

Tokoh utama dalam dongeng SIDB bernama Suri Ikun yang memiliki semangat kerja yang tinggi. Ia rajin membantu orang tuanya bekerja di kebun. Selain itu, Suri Ikun bahkan memberikan ide-ide agar melakukan penanaman sayuran kembali yang sudah dirusak oleh babi hutan. Suri Ikun menyarankan agar tanaman tersebut dijaga tiap malam secara bergantian dengan keenam saudara-saudara laki-lakinya. Kutipan percakapan percakapan pertama ialah nilai kreatif dan kerja keras demikian.

"Suri Ikun selalu bersemangat dan bekerja keras dalam segala hal dengan selalu membantu ayahnya. Dia rajin menanam sayur-mayur dan memperluas areal perkebunan mereka. Hal ini menjadikan ayahnya bangga karena ia selalu bekerja keras untuk kepentingan keluarga."(SIDB).

Tokoh Suri Ikun memiliki kreativitas dan semangat yang tinggi dalam bekerja. Saat ia digambarkan sebagai tokoh yang gagal, namun ia tidak berputus asa. Bahkan ia membuat ayahnya bangga karena semangat yang dimiliki dan disertai gagasannya untuk berbuat hal baru melalui idenya. Hal ini merupakan perilaku yang baik, yang mesti ditanamkan dalam tiap diri seseorang. Ketika ingin meraih sesuatuhal, harus disertai dengan kerja keras dan kreatif.

Karya sastra merupakan cermin kehidupan untuk kehidupan yang bersifat pragmatis (Rahman, 2011). Membaca karya sastra penting sebagai pengalaman sehingga terjadi persepsi dan pengetahuan dan kepribadian yang bersifat positif. Begitupula karakter tokoh Suri Ikun dalam dongeng. Secara tidak langsung pada saat mendongengkan anak kita telah membangun kepribadian anak.

\subsection{Penolong dan Belas Kasih}

Kepedulian Suri Ikun pada tokoh burung kecil dalam dongeng merupakan sikap yang harus ditanamkan kepada setiap anak usia dini. Sikap peduli bukan hanya ditunjukkan pada manusia saja, tetapi juga pada semua makhluk yang ada dalam lingkungan sekitar kita seperti hewanm dan tumbuhan jika mereka membutuhkan pertolongan. Disisi lain, sikap belas kasih perlu dimiliki setiap anak agar memiliki kepekaan rasa terhadap lingkungan sekitarnya. Berikut digambarkan dalam kutipan.

"Suri Ikun menolong dua ekor
burung yang kelaparan karena
terperangkap dalam gua yang gelap
gulita. Kaki burung itu terluka. Suri
Ikun telaten merawat burung tersebut
dengan selalu memberikan makan
setiap hari. Akhirnya burung tersebut
tumbuh sehat dan besar. Pada suatu
waktu kedua burung itu membalas budi
baik Suri Ikun (SIDB)."

Menurut Sugiarti (2013), mengemukakan bahwa sikap tolong menolong, dengan penuh optimisme, kuat bekerja, selalu bersemangat; menjalin hubungan sosialisasi kepada orang lain; ramah dalam pergaulan, tidak bergantung pada rang lain, serta dapat menyesuaikan diri. Selain itu, sikap berani, dan befikir positif merupakan keinginan atau nawacita bangsa untuk menjadi insan berkarakter.

\subsection{Menghargai Prestasi}

Menghargai pemberian seseorang merupakan salah satu perwujudan bersyukur kita kepada Sang Pencipta. Setip orang kehidupannya selalu digunakan dalam kebaikan akan mendapat balasan yang baik pula. Sebagai orang tua kita perlu memberikan pemahaman dengan baik kepada anak sejak dini agar mereka selalu berlomba untuk berbuat kebaikan, misalnya dengan rajin salat, belajar, atau saling tolong menolong, agar manusia tersebut memperoleh amal kebaikan dan derajat yang tinggi, baik dari sisi manusia maupun dalam pandangan Tuhan Yang Maha Esa. Berikut kutipan dalam cerpen.

"Burung yang pernah ditolong oleh Suri Ikun memberikan hadiah kepada Suri Ikun berupa sebuah Istana lengkap dengan pengawal, dayang-dayang dan rakyatnya. Suri Ikun memimpin rakyatnya denganadil dan bijaksana. Suri Ikun juga diberikan permaisuri yang bagus perangainya. Suri ikun mencari orang tuanya untuk hidup bersama di Istana Kerajaan dan memanggil saudara- 
saudaranya hidup bersama meskipun mereka pernah mencederai Suri Ikun" (SIDB)

\subsection{Sikap Positif}

Sikap perasaan dan pemikiran positif perlu ditanamkan dalam diri anak. Meskipun tokoh Suri Ikun mendapat perlakuan tidak baik oleh keenam saudaranya, ia tetap membalas dengan kebaikannya. Ia ingin mengajak orang tua dan keenam saudarany untuk tinggal dalam istananya. Seseorang yang senantiasa selalu berbuat baik akan selalu mendapat keberuntungan dalam kehidupannya. Ia akan banyak disenangi orang lain. Berikut kutipan dalam dongeng.

"Suri Ikun berusaha menemukan kedua orang tuanya dan saudaranya yang berjumlah 13 orang untuk menetap di istana kerajaan bersama Suri Ikun." (SIDB)

Meskipun setiap manusia diciptakan berbeda-beda begitupula dengan sikapnya. Keburukan tidak seharusnya dibalas dengan keburukan. Suri Ikun selalu mendapat perlakuan jahat terhadap keenam saudara lakilakinya, namun ia selalu bersikap positif. Membalas dengan kebaikan kepada seseorang merupakan suatu hal yang luar biasa jika orang lain pernah berbuat buruk kepada kita. Sikap seperti ini merupakan sikap terpuji yang perlu ditanamkan oleh manusia untuk menjalani kehidupan. Orang yang berbuat jahat tidak akan mampu mengalahkan kebaikan seseorang. Begipula dengan anak, perlu ditanamkan sikap positif dalam dirinya agar memiliki rasa kasih sayang terhadap sesama, selalu berprasangka baik,agar hubungan sesama manusia tetap terjaga.

\subsection{Kejujuran}

Kejujuran adalah hal utama yang perlu dimiliki seseorang. Tanpa kejujuran kita akan sulit mendapat derajat yang mulia. Orang lain tidak akan percaya jika kita tidak jujur. Sulit menjalin hubungan yang baik jika tidak disertai kejujuran. Tokoh Ikun dalam dongeng mengisahkan perilaku anak yang jujur, meskipun ia selalu disiasati dengan perbuatan jahat oleh keenam saudara laki-lakinya. Namun, karena perilakunya yang jujur, penyayang, kerja keras, penolong dan belas kasih, maka ia mendapatkan pujian oleh sang ayah, serta ia mendapat gelar menjadi seorang raja.

"Namun, ada beberapa ciri dan sikap yang digunakan dalam tokoh cerpen yang bertentangan dengan nilai pendidikan karakter seperti kutipan berikut ini.

"Sang ayah menyuruh ketujuh anak lelakinya menjaga kebun dari serangan hama babi. Namun, sayangnya anak-anak tersebut tidak mematuhi perintah sang ayah. Hanya Suri Ikun yang selalu telaten menjaga kebun dari serangan hama babi. Siang malam dia menjaga kebun tanpa dibantu oleh saudaranya yang lain (SIDB)."

Dari kutipan tersebut nilai yang bersifat negatif adalah perilaku licik dan rasa takut yang tercermin dalam sikap tokoh enam saudara Suri Ikun dalam dongeng SIDB. Perilaku licik atau pandai menipu, curanghanya dapat merugikan orang lain. Perilaku tersebut jika tertanam sampai saat dewasa akan berdampak buruk, baik bagi diri sendiri maupun orang lain. Perasaan takut hanya kepada Tuhan. Oleh karena itu, hendaknya kita hanya meniru perilaku berbudi luhur yang ada dalam cerita dongeng agar menjadi prinsip atau pegangan dalam menjalani kehidupan yang lebih baik.

Dongeng Suri Ikun dan Dua Ekor Burung merupakan jenis sastra tradisional. Lukens (2003) membagi enam jenis sastra anak, yaitu: fantasirealize, puisi, fiksi formula, sastra tradisional, biografi dan buku informasi. Psikologi media dan interaktivitas dalam komunikasi memungkinkan kita memahami proses empati dan identifikasi karakter (Soto and Laura Asymeric, 2010, hlm. 822). Sastra merupakan media pembelajaran yang digunakan secara reseptif, penerima dan dan ekspresif, kemampuan sebagai media pengajaran karakter (Wulandari, 2015, hlm. 68).

Pendidikan karakter memiliki esensi dan makna yang sama dengan pendidikn moral dan pendidikan ahlak. Tujuannya supaya anak memiliki kepribadian yang baik. (Ariyastana, 2017, hlm. 198).

Dongeng Suri Ikun dan Dua Ekor Burung sangat bagus untuk dijadikan pada bahan pelajaran pada anak-anak di sekolah. Nilai-nilai yang ditumbuh kemabangakan dalam diri peserta didik berupa nilai-nilai dasar yang disepakati secara nasional. Nilai-niai yang dimaksud di antaranya kejujuran, tanggung jawab dan peduli kepada orang lain (Suyitno, 2012, hlm. 2). 
Diasumsikan bahwa pesan persuasif tradisional berisi daftar argumen yang disajikan dengan cara yang eksplisit, sedangkan narasi dianggap tidak mengandung argumen eksplisit melainkan untuk mengilustrasikannya melalui penyajian acara, karena tindakan difokuskan pada karakter utama dalam cerita. Selain itu, telah dicatat bahwa pesan persuasif tradisional menunjukkan tujuan pendidikan-sikap yang jelas, sedangkan format narasi disajikan sebagai hiburan dan dirancang untuk kesenangan (JuanJose, \& Jair Vega Casanova, 2015).

Suri Ikun merupakan tokoh dalam dongeng yang mengajarkan berbagai macam nilai seperti nilai moral. Tokoh Suri Ikun tidak balas dendam kepada saudara-saudaranya meskipun mereka telah menyakitinya. Karya sastra merupakan media yang efisien untuk mengajarkan segala sesuatu seperti sains, nilai moral, nilai budi pekerti, dan nilai agama. Karya sastra berusaha menyampaikan nilai-nilai pendidikan yang merupakan refleksi dari kehidupan nyata sebagai hasil renunngan relita kehidupan yang dilihat (Febriana, Harris E.T., dan Ermanto, 2014,hlm.98).

Selain itu, tokoh-tokoh fiktif, sebagian besar waktu, adalah apa yang membuat naratif narasi fiksinnal sama sekali. Narasi fiksional menggambarkan serangkaian peristiwa yang terjadi di lingkungan dan semuanya adalah pendidikan karakter (Leclerc, 2016, hlm. 72). Pada era modern ini pendidikan karakter lebih meluas pada berbagai media antara lain televisi. Seperti (McLaughlin, 2018, hlm. 1) menerapkan konsep identifikasi stereotip - ide yang secara kognitifdan secara emosional mengidentifikasi dengan karakter minoritas fiktif secara bersamaan meningkatkan penerimaan mi Seperti noritas, sambil memperkuat stereotip tentang bagaimana mereka terlihat, bertindak, dan berbicara dengan konteks karakter televisi Latina. Secara khusus, kami mempekerjakansurvei nasional mengukur paparan peserta terhadap karakter TV Latina, tingkat Dostoyevsky tampaknya menerima kecenderungan ke arah otobiografi tertentu dalam penciptaan karakter, mungkin bukan sebagai makhluk berdasarkan pengalaman penulis sendiri, melainkan, mengikuti Sartre, karena fakta bahwa tidak mungkin ada 'menjadi' jika 'menjadi' belum ada (Garcia, 2015, hlm. 195).

Tokoh Suri Ikun merupakan tokoh sebagai pejuang dalam rumah tangga atau keluarga, pahlawan yang berani mengejar hama babi. Tokoh Arthur Margon dengan ringkas menyatakan bahwa kepahlawanan kesusastraan Amerika abad kesembilan belas didefinisikan oleh moralitas dan individualisme. Meskipun Individualisme yang kuat jelas merupakan pusat karakterisasi McCarthy, sulit untuk mendeteksi moralitas dalam kekerasan, penyimpangan dan penyimpangan yang mendorong narasinya. Namun, ada beberapa karakter dalam fiksi McCarthy yang sepertinya cocok dengan konsep Margon tentang pahlawan abad kesembilan belas.

Apapun gayanya, apa pun lingkungannya, pahlawan diharapkan untuk menggabungkan dua tradisi - yang didasarkan pada pengertian tugas publik dan "karakter", yang lain menekankan keberhasilan dan kekuatan individu untuk mengendalikan lingkungan dan dengan demikian menghasilkan pahlawan yang merayu individualisme dengan pribadi. moralitas dan rasa kewajiban publik, dan dengan demikian menghindari keegoisan (Bukarova, 2017, hlm. 174). Karakter dalam karya sastra diperankan dalam bentuk orang, binatang atau benda sebagai subjek dalam cerita (Eka, 2017, hlm. 5) seperti dalam dongeng dua ekor burung yang bias berbicara seperti manusia.

Seharusnya karya sastra memunculkan nilai-nilai pendidikan yang positif dan negatif secara seimbang. Kedua hal tersebut dapat dijadikan patokan bagi pembaca dalam melangkah dalam kehidupan sehari-hari. Seperti dalam dongeng terjadi budaya gotong royong dalam melakukan pekerjaan berkebun. Kemunculan nilai pendidikan negatif dan positif sama dengan nilai sebab akibat dalam kehidupan yang sebenarnya. Penyamapaian sastra yang lebih mengunggulkan nilai pendidikan positif dapat dilihat dalam nilai pendidikan: religius, sosial, moral, dan budaya (Puspitasari, Herman J.Waluyo, dan E.Wardhani, 2017, hlm.15).

Pendidikan karakter perlu dilakukan pada semua pelajaran, pendidikan karakter di sekolah belum berjalan fektif (Nugrahani, 2017, hlm. 116). Fiksi Indonesia abad ke-21 menggunakan cerita dan karakter boneka sebagai referensi budaya. Aktualisasi kembali karakter dan cerita pewayangan umumnya digunakan sebagai referensi budaya dalam hal pemberian nama, perbandingan (metaforis), pendidikan anak-anak, dan sumber reinkarnasi sejalan dengan keyakinan agama. Mengacu pada nama-nama boneka, karakter, dan cerita dipandang lebih efisien dan komunikatif karena bersifat tipologis, mengikuti arus utama, dan 
jelas. Nilai dalam cerita dan tokoh boneka banyak diambil sebagai salah satu sumber referensi dan sarana pendidikan anak oleh orang tua. Dalam agama Hindu, yang mengakui reinkarnasi, tokoh-tokoh wayang bahkan menjadi salah satu sumber bagi makhluk hidup yang pada saatnya akan bereinkarnasi selama kehidupan selanjutnya.

\section{Simpulan}

Sastra anak merupakan karya yang dikhususkan bagi anak. Kandungan isi bukubuku sesuai dunia, minat dengan tidak mengesampingkan aspek emosional dan intelektual anak. Melalui menceritakan atau mendongengkan kita dapat meningkatkan daya imajinasi, emosional, intelektual, rasa sosial, rasa etis dan religious. Oleh karena itu, orang tua perlu memilihkan jenis dongeng yang benar-benar sesuai dengan perkembangan anak.

Hasil analisis dongeng "Suri Ikun dan Dua Ekor Burung" disingkat (SIDB) ditemukan nilai pendidikan karakter berupa, nilai kreatif dan kerja keras, penolong, menghargai prestasi, sikap positif dan kejujuran. Namun, ada beberapa ciri dan sikap yang digunakan dalam tokoh cerpen yang bertentangan dengan nilai pendidikan karakter, seperti sifat licik dan penakut. Oleh karena itu, seorang pendidik atau orang tua yang baik perlu memilah isi bacaan. Kedua orang tua seharusnya memberikan edukasi kepada anak supaya anak mengerti sikap yang baik untuk dijadikan contoh dalam kehidupan melalui bacaan dongeng.

Penelitian mengenai nilai-nilai karakter dalam karya sastra perlu dieksplorasi secara maksimal. Karya sastra tradisional dan modern memiliki banyak pndidikan nilai karkter. Oleh karena itu, perlu pemilahan terhadap karya sastra yang kaya akan nilai pndidikan karakter khususnya untuk pembentukan karakter pada anak usia dini.

\section{Daftar Pustaka}

Adhi, M.K. (2014). "Model Pendidikan Karakter Berbasis Mendongeng."Jurnal Santiaji Pendidikan, (1),hlm.1-12.

Afandi. (2011). "Integrasi Pendidikan Karakter dalam Pembelajaran IPS di Sekolah Dasar."Jurnal Pedagogia, 1 (1),hlm. 8598.

Ariyastana, I Wy. (2017). Insersi Nilai-Nilai Karakter Bangsa pada Materi dan Proses Pembelajaran Bahasa Indonesia." Jurnal
Ilmiah Pendidikan dan Pembelajaran, PPS Universitas Pendidikan Ganesha, JIPP, 14(3),hlm. 196-207.

Bukarova, Zuzana.(2017). “Obscure Characters in Cormac Mccharty's Fiction." Papol Jozef Safarik, University in Kosice, hlm. 171-181.

Eka.(2017). "Revisiting Character Education from Islamic Perspective: A Ques for Character-Based Education in Indonesia. Ulumuna, Journal of Islamic Studies, Stated University Mataram, 21(1), hlm. 132.

Febriana, Noni, Harris E.T., dan Ermanto. (2014). Nilai-Nilai Pendidikan Karakter dalam novel Rantau Satu Muara Karya Ahmad Fuadi: Tinjauan Sosiologi Sastra." Jurnal Bahasa, sastra dan Pembelajarannya, 2(3),hlm. 92-107.

Garcia, Benami Barros. (2015). Around the Function of Chaacter in Literary Fiction.London: Universidad de Oxford.

Ikhwan, Wahid Hoirul.(2013). "Upaya Menumbuhkan Karakter Anak Dalam Pembelajaran Sastra Anak dengan Model Play Learning dan Performance Art Learning di SDN Banayuh 4."Widyagogik, 1(1), hlm.70-84.

Juan-José,Igartua \& Jair Vega Casanova. (2015): Identification With Characters, Elaboration, and Counterarguing in Entertainment-Education Interventions Through Audiovisual Fiction, Journal of Health Communication, hlm.1-8, DOI: 10.1080/10810730.2015.1064494.

Kristiani, D. (2017). "Suri Ikun dan Dua Ekor Burung."Kompas, tanggal 15 Oktober 2017. Lakonhidup.com.

Leclerc, André. (2016)." Actualism and Fictional Characters." Principia, 20(1),hlm. 61-80.

Lukens, Rebecca J. (2003). A Critical Hanbook of Children's Literature. New York:Longman.

McLaughlin, B., Rodriguez, N.S., Dunn, J., \& Martinez, J. (2018). Stereotyped Identification: How Identifying with Fictional Latina Characters Increases Acceptance and Stereotyping. Mass Communication \& Society. Advanced 
online publication. doi: 10.1080/15205436.2018.1457699.1-37

Nugrahani, Farida (2017)."Pendidikan Karakter Mellui Pembelajaran Bahasa Indonesiadengn Materi Membaca Novel Sastra." Jurnal Edudikara, 2(2), hlm.113124.

Nurgiyantoro,B. (2016). Sastra Anak. Yogyakarta. Gadjah Mada University Press.

Nurgiyantoro, B.(2010). Sastra Anak dan Pembentukan Karakter. Cakrawala Pendidikan, Jurnal Ilmiah Pendidikan.HIm. 25-40.

Oktavianus, Ike Revita, dan Dian Astri. 2014. "Penggalian Nilai-Nilai Antikorupsi Dari Peribahasa Minangkabau Sebagai Upaya Pembangunan Karakter Bangsa." Jurnal Pustaka Budaya, 1(1),hlm.1-2.

Puspitasari, Rosika Herwin, Herman J.Waluyo, dan E.Wardhani, (2017)."Kajian Sosiologi Sstra da Nilai Pendidikan Karakter pada Novel Cantik Itu Luka."Aksara, 2(1),hlm. 1-14.

Rahman, F. (2011). "Sastra Anak dalam Persimpangan."Hasanuddin University, URI:

http://repository.unhas.ac.id/handle/12 $3456789 / 27225$

Septiana, T.I. (2012). “Implementasi Pendidikan Karakter dalam Pembelajaran Bahasa dan Sastra."Jurnal Evaluasi Pendidikan, 2 (1), hlm. 1-8.

Setiawati, Lis. (2015). "Pembentukan Karakter Siswa Melalui Pembelajaran Bahasa dan Sastra Indonesia." Jurnal Pendidikan, 16(1), hlm.65-73.

Soto,Maria T. and Laura Asymeric (2010). "Impacto de la interactividad en la identifi cación con los personajes de fi cciones." Psicothema ,PSOTEG, 22, (4), hlm. 822-827

Sugiarti. (2013)."Kajian Sastra Anak “Kecil-Kecil Punya Karya The Evergreen" Karya Nisrina Hanifa dalam Perspektif Pendidikan Karakter."Jurnal Humanity, 8 (2)hlm.94-105.
Suprapto,Lina, Andayani, dan Budi Waluyo.(2014). "Kajian Psikologi Sastra dan Nilai Karakter Novel 9 dari Nadira Karya Leila S. Chudori." BASASTRA, Jurnal Penelitian Pendidikan, Sastra Indonesia dan Pengajarannya,2(3), hlm.1-15.

Suryaman, M. (2010)."Pendidikan Karakter melalui Pembelajaran Sastra."Cakrawala Pendidikan, Jurnal Ilmiah Pendidikan, Vol. - 112-126.

Suyitno, Imam. (2012)."Pengembangan Pendidikan Karakter dan Budaya Bangsa Berwawasan Kearifan Lokal."Jurnal Pendidikan Karakter,2 (1), hlm.1-13.

Untari, M.F.A., dkk.(2012)."Pengembangan Cerita Anak berwawasan Budi Pekerti bagi Pendidikan Karakter."Journal of Primary Educational, 1(1) hlm.1-5.

Wulandari, R.A. (2015). "Sastra dalam Pembentukan Karakter Siswa."Jurnal Edukasi Kultura, 2 (2),hlm.63-73.

Yasid, A. (2012). "Membangun Karakter Peserta Didik dalam Bingkai Drama: Kajian Pendidikan Karakter Berbasis Karya Sastra."Jurnal Pelopor Pendidikan,3(1),hlm. 43-52. 